\title{
Strengthening the Construction of Students' Archives to Serve for the Innovative Employment
}

\author{
Shuiying Wang a and Chaohua Deng ${ }^{b}$ \\ ${ }^{1}$ Department of Personnel, Jingdezhen Ceramics University, Jiangxi 343003, China; \\ a1459087023@qq.com; b490355887@qq.com
}

\begin{abstract}
Colleges and universities are talent training base, Students' employment is the lifeline of the Colleges. How to improve the quality of student records management, to provide students' comprehensive archives information during the period of school including morality, intelligence, physical education, art education and Labor education for employers, and can fully understand the student's comprehensive quality, offer the safeguard protection for society to select talents. It is an era that college students choose their own career, the employment problem has become a big problem in the college management and development. In order to effectively alleviate the employment pressure, improve graduates employment rate, this paper puts forward the employment of university graduates file archiving and management methods, in order to promote graduates employment service, this paper expounds flexible connection between graduates, market and colleges, to extend the functions of archives in colleges, serving for the employment of graduates.
\end{abstract}

Keywords: Students; Files; Employment; Service

\section{加强学生档案建设, 为创新就业服务}

摘要: 高校是人才培养基地, 学生就业是高校生命线。如何提高学生档案管理质量, 为用人单位提供提学生在校期间的 高德、智、体、美、劳等全面的档案信息, 并充分了解学生的综合素质, 为社会选用人才提供保障。当前高校学生自主择业 时代, 就业问题成为了高校管理与发展所面临的一大难题。为了有效缓解高校就业压力, 提高毕业生就业率, 本文提出了高 校毕业生就业档案归档及其管理方法, 并论述学生档案在毕业生、就业市场与高校之间的灵活衔接, 扩展高校档案馆职能作 用, 为提升毕业学生就业服务。

关键词: 学生; 档案; 就业; 服务。

引言

高校是人才培养基地, 是单位选用人才的主要来源。学生就业是高校向社会输送人才的重要途径, 是 用人单位了解和评价高校的主要窗口, 也是学生跨出大学之门走向社会迈出关键一步。学生档案应体现学 生所拥有的全面人才素质信息。因此, 学生档案是用人单位录用人才决策的重要依据, 对于学生的就业、 发展等有着举足轻重的作用, 其次, 学生就业是高校输出人才的出口站, 是高校生命线。如何将学生档案 管理好, 是高校档案工作的重点, 在此笔者针对当前高校学生档案信息不全, 管理不规范以及就业档案中 出现的问题进行分析, 研究学生档案管理新方法。

\section{1 目前高校学生档案管理的现状.}

\section{1 材料信息不全, 人才特征不能展示}

当前高校学生档案归档仅限于高校招生录取表、入学登记表、学籍表、成绩表、毕业登记表、政审、 奖惩材料、入党 (入团)、就业存根、体检表等。档案归档材料单一, 局限于课堂教学成绩, 不能全面反映 学生的个性特征、思想道德、心理素质和能力, 给用人单位带来不便。 


\section{2 高校学生档案管理不当}

一般高校将学生档案招生录取后分班存放于就业办, 对学生档案未作系统管理, 当学生毕业之际, 临 时增补在校期间所形成的档案材料, 但不作档案整理, 档案未鉴定、未分类, 管理草率, 就业档案零乱, 学生档案管理质量存在问题, 对学生就业提取信息带来困难。

\section{3 学生档案未进行信息化管理}

当前高校学生档案以封闭式保管, 档案信息资源未进入系统管理, 学生不能查阅个人档案信息, 就业 时只能自己撰写应聘书, 不能正确、真实的获取和利用学生的德、能、勤、绩等档案资源信息, 用人单位 不能通过应聘材料全面了解学生档案信息, 而遗误人才选用。

\section{2 讨论(研究方法)}

当前高校学生档案管理状况已严重影响到学生就业, 给用人单位招录人才和使用人才造成不便。针对 当前高校学生就业档案管理出现的问题, 本人提以下几点解决的思路和方法。

\section{1 改变思想观念, 加强学生档案管理}

第一, 高校要重视学生档案建设。学生是高校的重点工作，学生档案是在校期间唯一的真实记录。高 校在重视学生课堂教育工作的同时应加强学生档案的管理, 学生成功就业、实现自我发展的关键是全面丰 富的在校档案信息资源, 是用人单位了解和使用人才的重要依据, 是检验高校专业设置是否与社会人才需 求对口的重要体现。高校学生档案应增加在校期间的思想道德品行、心理素质、社会实践、动手操作能力 等综合测评记录档案材料, 让学生档案再现学生个性素质, 让学生档案 “活” 起来。第二, 辅导员、班主 任要提高学生就业档案的认识, 了解学生档案的重要性, 指导学生认真填写档案材料内容; 第三, 主管学 生档案工作人员要提高学生档案管理意识, 正确认识到学生档案是干部人事档案的一部分, 加强学生档案 管理，提高学生档案的管理质量，为学生就业提供丰富档案信息内容，促进学生就业。

\section{2 将学生档案划入档案馆统一管理}

学生档案管理是高校重要工作之一, 学生档案是整体档案的一部分, 也是一种特殊的流动性档案, 其 管理方式可按干部人事档案进行十类分类鉴定、归档, 进行编目、装订, 将学生档案有序管理, 为学生就 业提供优质档案信息。第一，体现高校管理能力。就业档案是高校管理工作对外的窗口，也是高校向用人 单位和社会展示管理水平的一种途径, 有句老话说的好: “一叶知秋” ; 第二, 对学生就业有利, 丰富的 学生档案, 可以全面反映学生的综合素质和能力, 便于单位审阅档案, 选用合适的人才; 第三, 建立毕 业生就业档案管理制度。对基层档案管理员进行业务培训与指导; 积极做好学生和教工的就业档案管理 的引导工作，突出该项工作在高校工作中的价值与意义 [1]。

\section{3 加强学生档案的真实填写}

真实有效的学生档案为学生就业提供准确的信息。高校辅导员和班主任必须认真指导学生填写档案信 息, 发现问题及时更正, 保质保量从源头填好档案。这是对学生就业、未来工作和发展负责, 也是对高校 负责, 有利于高校向社会和用人单位交一份满意答卷。另一方面学生档案是学生本人未来人生发展的重要 借签材料, 高校是学生曾经学习的地方, 是学生整个人生中无比美好的阶段, 学生档案真实、准确、全面 地记载着这段人生最鲜活的历史, 学生档案材料的收集要完整、齐全; 文字材料的纸张规格要统一、书写 要规范、字迹要工整 [2], 才能展示学生的德、能、勤、绩等全方位情况, 帮助他们获得良好的就业和发 
展, 学生档案反映人生的成长足迹, 可供回忆、自省、提升, 对于学生以后发展有重要的价值和意义 [3]。 优质完善的学生档案, 可以让人生更加完满。

\section{4 突出学生的德、智、体、能综合素质}

高校应丰富学生档案内容, 注重思想品德和技能档案的收集和归档。第一, 丰富思想品德档案。高校 一般开设《思想品德养修》、《毛泽东概论》和《马克思主义原理》作为思想品德教育的主要授课材料, 这些思想品德课的开设是非常重要的、不可缺少的, 但是当前高校思想品德教育只重视课堂教学, 而忽视 了学生社会生活中的思想道德行为实践和评价, 造成学生档案个人品德材料缺乏; 第二, 应重视学生专业 技能训练和评价。学生档案体现学生业绩的只有学生在校成绩和论文答辩类档案, 对学生的社会实践记录 只有合格、良好等, 对其技能没有更精确的评价; 第三, 建立大学生诚信档案。内容应包括学生的基本信 息和学生助贷、还款、信用卡还贷等信用信息, 以及学生在校期间的日常行为记录、班级同学之间诚信互 评信息等 [3]。市场经济运行必不可少的一个条件就是 “诚信” , 越来越多的用人单位更看重学生的诚信 意识, 高校在收集学生档案的同时应建立学生诚信档案 $[4]$ 。第四, 高校应重视学生就业后跟踪情况。高 校应加强对学生就业后在社会上工作、学习、生活、成才发展情况跟踪调查和统计。这项工作是衡量学生 综合素质及高校的教育水平和管理能力的重要评估标准, 应及时对就业学生跟踪调查, 全面了解就业学生 工作后的状况。第五, 高校必须重视学生在思想品德方面建设。加强对学生思想品德行为的评价, 将考察 评价材料加盖公章存档, 加强对学生技能测试, 对训练技术能力进行评价, 积极提高学生动手能力; 第六, 建立创业教育资金与奖励档案。高校应为大力支持大学生的创业活动, 设立创新创业专项资金, 鼓励有强 烈意愿或有极佳潜力的大学生创业, 积极扶持他们的创业实践; 设立创新创业教育专项奖励, 奖励取得科 技创新成果和在相关竞赛中获奖的学生、指导教师和相关院系; 设立创新创业奖学金, 表彰在创新创业方 面表现突出的学生 [5]。第七, 学生应重视个人思想品德修养。不断在课外加强学习和锻炼, 注意平时的 积累, 注意自己的举止言谈, 以达到品学兼优, 储备能力, 为就业提供更丰富和有利用价值的档案, 创新 就业条件。

\section{5 创新改革, 让学生档案管理 “动” 起来}

构建高校学生档案内容指标体系。不断完善高校学生档案内容体系是开展学生档案管理工作的基础。 “以就业为向导” 的高校学生档案管理工作已成为现代社会档案管理发展的重点, 很多档案界专家学者认 为高校学生档案管理存在内容不完整、服务不到位等问题, 不能正确反映高校学生整体素质, 应根据教育 教学改革的实际需求完善归档材料 $[6]$ 。第一, 高校要改变对学生档案保管式、静态式管理, 加强学生档 案的系统管理, 建设全过程的、动态的、规范的、科学的学生档案管理机制, 使学生档案管理 “走” 出保 管室, 进入学生的日常管理和服务就业工作之中。第二, 学生应重视自己在校档案, 不断加强自身的档案 意识。认真了解现代高校学生档案归档内容和程序, 积极详实地按学校要求和规定认真填写, 按程序递交 学生档案资料, 不要忽视、淡漠或遗弃学生档案资料, 要学会利用档案来拓展自己的就业和发展渠道, 完 善自己的人生。

\section{6 建立学生档案信息库}

高校学生就业, 需提供完整、丰富的档案信息。避免泄露大学生的个人隐私和商业机密, 确保档案信 息的安全, 建立健全数字化信息管理 
系统和一个比较完善的创业档案信息库 [7]。引进先进技术，提高档案管理信息化水平。根据实际情 况运用计算机软件来进行学生档案管理。一是建立学生的电子档案。将学生的基本信息录入数据库, 建立 录入、审核、查询、修改、打印等议题的计算机软件系统, 可以通过计算机系统进行迅速、有效、多角度 的整理, 保证了档案管理的标准化和规范化。二是校内联网, 实现信息资源的共享, 满足不同的需求, 用 最便捷、最快速方式给予最有效的利用 $[8]$ 。

\section{7 开拓机制, 发挥学生作用}

让学生档案 “融” 进去。现代高校要使高校学生档案充分地服务于学生就业, 要将学生档案管理工作 融入学校日常的人才培养工作和重要议事日程之中, 成为学校教育教学等各项管理工作的有机组成部分, 作为干部年度绩效考核的重要评估指标和内容 [9]。

\section{8 加强学生就业档案传递}

当前学生就业档案不是机要传递, 而是各种快递传送, 档案的传递过程易出现问题, 造成档案下落不 明, 导致档案丢失的严重后果, 必须加强就业档案传递的监督和追查 [10]

\section{3 结论}

综上所述, 高校学生档案是学生就业过程中必不可少的、宝贵的、唯一证据。高校学生档案储备着大 量的、丰富的、有价值的人才信息, 有利于就业人才资源开发和利用。创新高校学生档案管理方法和模式, 必须以学生就业为高校发展的动力和中心工作, 采用科学的管理方法, 合理培养学生综合素质, 提高学生 的专业技术能力, 不仅有利于学生就业, 也利于高校自身建设和发展。创新和改革高校学生档案管理, 首 先必须重视学生档案材料来源的收集、整理, 充实和丰富学生档案信息, 进行系统管理, 拓展学生档案管 理的新思路、新办法, 积极管理人才档案, 提高学生各项应聘素质; 高校要以学生就业为导向办学, 发现 人才应加以保护和推荐, 使人才脱颖而出, 创造更好的学生就业氛围和环境, 提高毕业学生就业率。高校 要站在人才管理与人才竞争的角度, 本着 “以人为本” 的思想, 创新学生档案管理手段, 提高学生的档案 意识, 以优质的学生档案管理推动就业, 切实集合实体档案与电子档案的各自优势, 构建和完善高校学生 档案服务体系, 实现服务供需对接 [11]。为用人单位输送优秀人才, 为就业学生找到更合适和满意的工作, 为行业和社会服务。

\section{参考文献:}

[1] 姜献群. 高校毕业生就业档案管理模式探析. [档案学通讯, 2013] (6)：17-17

[2] 王秀君. 高校学生档案管理工作的问题及对策文. 山东档案，2015(6)：33-33

[3] 蔡金君. (高校学生档案工作服务学生就业的若干思考. 浙江档案, 2015 (6)：60-60

[4] 赵晓玲、陈小强. 加强高校学生档案管理满足学生就业需求. 科技世界. 2013 (12)：238-238

[5] 刘 萌. (适应创业教育的高校档案管理研究. 浙江档案, 2016. (9)：57-57

［6］禇宝良. 高校学生就业档案的有效建立与开发利用. 兰台世界, 2014 (4 中旬)：72-72

[7] 左飞. 大学生就业管理中创业档案的作用研究. 山西档案, 2016 (5)：83-83

[8] 朱丽. 加强高校学生档案管理 做好为大学生就业服务工作. 山东档案, 2012 (6)：53-53

[9] 管弦. 创新以就业为导向的现代高校学生档案管理. 中国档案, 2013 (7)：57-57

[10］王云庆 何蔓. 大学毕业生档案管理中的问题与对策. 山东档案, 2016 (3)：39-39

[11］庞晓敏. 服务就业视角下的高校学生档案管理研究., 兰台世界, 2014(10)：79-79 


\section{References:}

[1] Jiang Xianqun. Analysis on college graduate employment file management model. Archives Communication, 2013, (6): 17-17

[2] Wang Xiujun. Problems and countermeasures of archives management in college students. Shandong Archives, 2015 (6): 33-33

[3] Cai Jinjun. Series of thinking on college students archives work to serve for the employment of graudates. Zhejiang file, 2015 (6): 60-60

[4] Zhao Xiaoling, Chen Xiaoqiang. Strengthen the management of college students file to meet the needs of students. Technology World .2013 (12): 238-238

[5] Liu Meng. Research on adaptation to the education of college archives management. Zhejiang Archives, 2016. (9): 57-57

[6] Chu Baoliang. College students employment file of the effective establishment, development and utilization. Lantai World, 2014 (4): 72-72

[7] Zuo Fei. Research on the role of entrepreneurial archives in college students' employment management. Shanxi Archives, 2016 (5): 83-83

[8] Zhu Li. Strengthen the management of college students file management for college students employment services. Shandong file, 2012 (6): 53-53

[9] Guan Xian. Innovative employment-oriented management of modern university students. China Archives, 2013 (7): 57-57

[10] Wang Yunqing He Man. Problems and countermeasures in archives management of university graduates. Shandong Archives, 2016 (3): 39-39

[11] Pang Xiaomin. Study on the management of college students' archives from the perspective of service employment. Lantai World, 2014 (10): 79-79 